\title{
Microstructural Characteristics and Mechanical Properties of Friction Stir Spot Welded 2A12-T4 Aluminum Alloy
}

\author{
Huijie Liu, ${ }^{1}$ Yunqiang Zhao, ${ }^{1}$ Xingye Su, ${ }^{2}$ Lilong Yu, ${ }^{1}$ and Juncai Hou ${ }^{1}$ \\ ${ }^{1}$ State Key Laboratory of Advanced Welding and Joining, Harbin Institute of Technology, Harbin 150001, China \\ ${ }^{2}$ School of Chemical Equipment, Shenyang University of Technology, Liaoyang 111003, China \\ Correspondence should be addressed to Huijie Liu; liuhj@hit.edu.cn
}

Received 17 May 2013; Revised 21 July 2013; Accepted 23 July 2013

Academic Editor: Jenn-Ming Yang

Copyright (c) 2013 Huijie Liu et al. This is an open access article distributed under the Creative Commons Attribution License, which permits unrestricted use, distribution, and reproduction in any medium, provided the original work is properly cited.

\begin{abstract}
2A12-T4 aluminum alloy was friction stir spot welded, and the microstructural characteristics and mechanical properties of the joints were investigated. A softened microstructural region existed in the joint, and it consisted of stir zone (SZ), thermal mechanically affected zone (TMAZ), and heat affected zone (HAZ). The minimum hardness was located in TMAZ, and the average hardness value in SZ can be improved by appropriately increasing welding heat input. The area of complete bonding region at the interface increased with increasing welding heat input because more interface metals were mixed. In a certain range of FSSW parameters, the tensile shear failure load of the joint increased with increasing rotation speed, but it decreased with increasing plunge rate or decreasing shoulder plunging depth. Two kinds of failure modes, that is, shear fracture mode and tensile-shear mixed fracture mode, can be observed in the tensile shear tests, and the joint that failed in the tensile-shear mixed fracture mode possessed a high carrying capability.
\end{abstract}

\section{Introduction}

As a variant of the conventional friction stir welding (FSW), a new solid state joining technology called friction stir spot welding (FSSW) was developed in 1993 [1,2]. This new spot welding technique has been successfully applied in the automotive industry due to its high product quality, over $90 \%$ energy saving and $40 \%$ equipment cost saving versus the traditional resistance spot welding (RSW) [2]. In FSSW process, a rotation tool is inserted into the overlapping workpieces to an established depth and then held for a certain time before being retracted $[3,4]$.

Mechanical properties are critical for an FSSW joint which are mainly affected by tool geometry and process parameters, and a few of studies have been done in the past decade. For the welding tool, a concave shoulder is the most common design as a result of the highest effective top sheet thickness that can be achieved $[5,6]$. Tozaki et al. found that the tensile shear failure load increased with the increase of pin length for the 6061-T4 FSSW joints [5], while some other results indicated that the suitable pin length should be $50 \%-$ $70 \%$ of the total thickness [2]. The process parameters include rotation speed, plunge rate, shoulder plunge depth, and dwell time, which have a strong impact on the strength of joints. Yuan et al. [1] reported that for the spot welded joint of $1.0 \mathrm{~mm}$ thick $\mathrm{Al}$ alloy 6016-T4 sheet, the tensile shear failure load first increased and then decreased with increasing rotation speed from $1000 \mathrm{rpm}$ to $2500 \mathrm{rpm}$. On the other hand, some researchers reported that the joints tensile shear failure load decreased with the tool rotation speed [7-9]. Tozaki et al. [5] stated that the tensile shear failure load increased with the increase of tool dwell time because a wider bonding region can be achieved. But Zhang et al. [7] reported that the tensile shear failure load was almost independent of the given tool dwell time. In Yuan's report, with the shoulder plunge depth increasing, the joint strength firstly increased and then decreased, and the author also believed that the high shoulder plunge depth made the hook tip upward, which can reduce the effective thickness of the upper sheet $[1,10]$.

$2 \mathrm{~A} 12$ aluminum alloy is more suitable to manufacture aircraft parts such as skins and stiffeners due to its higher mechanical properties than 5xxx and 6xxx aluminum alloys. So it is significant to carry out the research on FSSW of $2 \mathrm{~A} 12$ aluminum alloy so as to replace the existing joining technique 


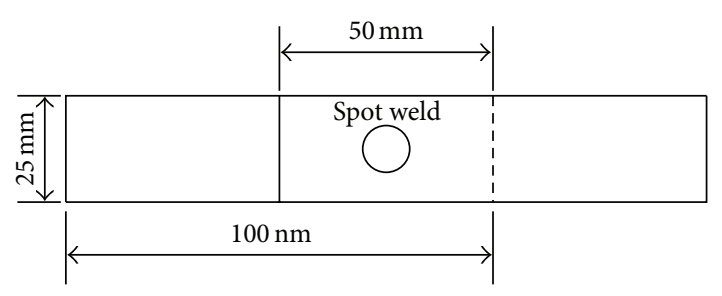

FIgURE 1: Configuration of tensile shear specimens.

TABLE 1: Chemical composition of 2A12-T4 aluminum alloy (mass fraction, \%).

\begin{tabular}{ccccccccr}
\hline $\mathrm{Cu}$ & $\mathrm{Mg}$ & $\mathrm{Mn}$ & $\mathrm{Zn}$ & $\mathrm{Fe}$ & $\mathrm{Si}$ & $\mathrm{Ti}$ & $\mathrm{Ni}$ & $\mathrm{Al}$ \\
\hline 4.1 & 1.5 & 0.66 & 0.88 & 0.33 & 0.24 & 0.02 & 0.01 & $\mathrm{Bal}$. \\
\hline
\end{tabular}

TABLE 2: Mechanical properties of 2A12-T4 aluminum alloy.

\begin{tabular}{lcc}
\hline Ultimate strength/MPa & 0.2\% proof strength/MPa & Elongation $/ \%$ \\
\hline 425 & 275 & 12
\end{tabular}

such as riveting and RSW because of the advantages of FSSW. But there is lack of the researches on FSSW technique of 2xxx aluminum alloys, including 2A12, and thus the exploration of FSSW technology of 2A12 aluminum alloy is in great need. The study focus was placed on the effect of FSSW parameters on interface bonding area, microhardness distribution, tensile shear failure load, and fracture feature, and the optimal technology parameters are obtained by our research work.

\section{Experiment Procedure}

2A12-T4 aluminum alloy sheets with $3 \mathrm{~mm}$ thickness were used as the base material (BMZ), whose chemical compositions and mechanical properties are listed in Tables 1 and 2. Figure 1 illustrates the configuration of tensile shear specimens employed. All the specimens were comprised of two $100 \mathrm{~mm} \times 25 \mathrm{~mm}$ sheets with an overlap area of $25 \mathrm{~mm}$ by $50 \mathrm{~mm}$, which were welded in the center of the overlap area. A welding machine (FSW-3LM-003), operated in the position control mode, was used to produce FSSW joints. Figure 2 shows the configuration and size of the welding tool employed which consisted of a round concave shoulder and a conical pin with right hand thread. The thread pitch was $0.75 \mathrm{~mm}$. The tilt angles of the concave and cone were $10^{\circ}$ and $15^{\circ}$, respectively. The diameters of the shoulder, root, and tip of the pin were $12 \mathrm{~mm}, 5.5 \mathrm{~mm}$, and $3.0 \mathrm{~mm}$, respectively, and the length of the pin was $4.35 \mathrm{~mm}$. A constant dwell time of $10 \mathrm{~s}$ was applied, and the range of rotation speed, plunge rate, and shoulder plunge depth were 400 1200 rpm, $5 \sim 40 \mathrm{~mm} / \mathrm{min}$, and $0.1 \sim 0.5 \mathrm{~mm}$, respectively.

After welding, metallographic samples were cut using an electrical-discharge cutting machine, and then they were sanded and polished. And the final surfaces of the metallographic samples should be guaranteed through the center line of spot welded joint. After that, the metallographic samples were etched with Keller's reagent, and metallographic analyses were carried out by optical microscopy (OM, Olympus-MPG3). Micro-hardness profiles were measured at

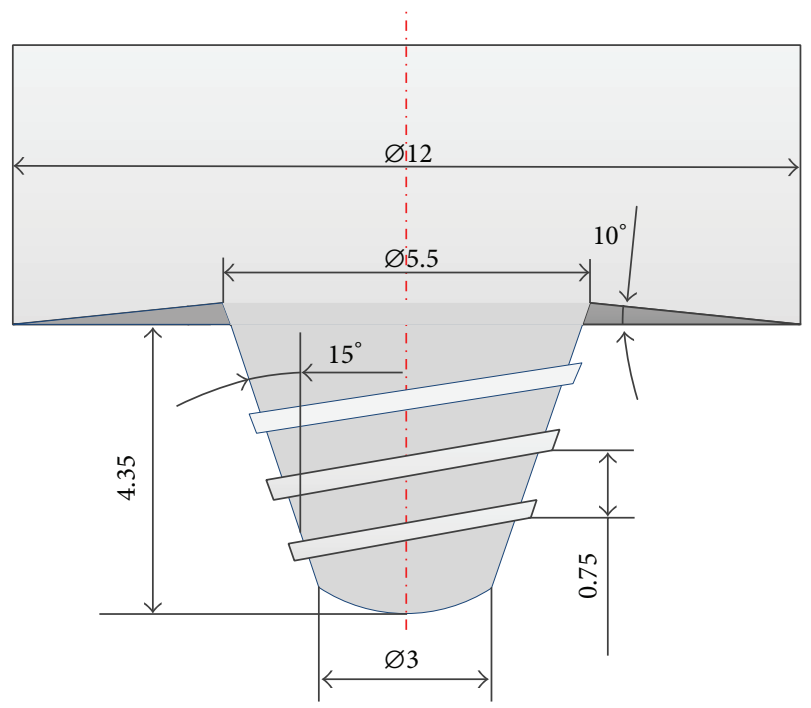

FIgURE 2: Configuration and size of welding tool.

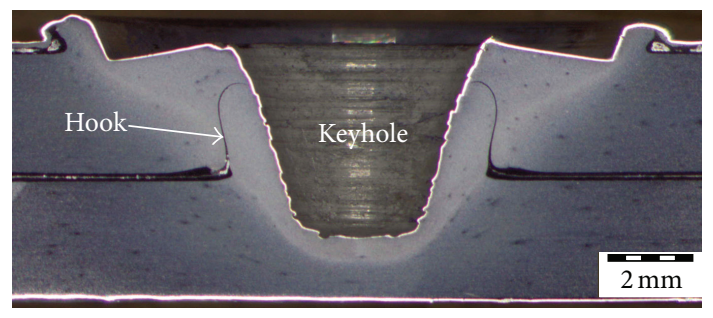

FIgURE 3: Cross-section of typical FSSW joint.

the midthickness of the upper sheets with a spacing of $1 \mathrm{~mm}$ between the adjacent indentations, and the average hardness values in $\mathrm{SZ}$ at the interface were also evaluated through three points. The testing load was $1.96 \mathrm{~N}$ for $10 \mathrm{~s}$. It should be noted that, owing to the axial symmetry the spot welded joint, hardness test was performed only on one side of the centerline. Tensile shear test was carried out on INSTRON-1186 mechanical properties testing machine. Tensile shear failure load of the joints under each parameter was evaluated through three tensile shear specimens. The bonding area at the interface was measured in order to clarify the influence of the bonding area on the tensile shear failure load. The fracture morphologies of the failure specimens were observed using a Hitachi-S3400N SEM scanning electron microscope.

\section{Results and Discussion}

3.1. Microstructural Characteristics. Figure 3 shows a typical cross-section of FSSW joint. A "keyhole" exists in the center of the spot welded joint. The upward curved "Hook" can be clearly seen, which is formed by the upward bending of the interface due to the penetration of the tool into the lower sheet [11-13].

3.1.1. Microstructural Zones. The cross-section can be divided into four microstructural zones, that is, base metal zone (BMZ), heat affected zone (HAZ), thermomechanically affected 


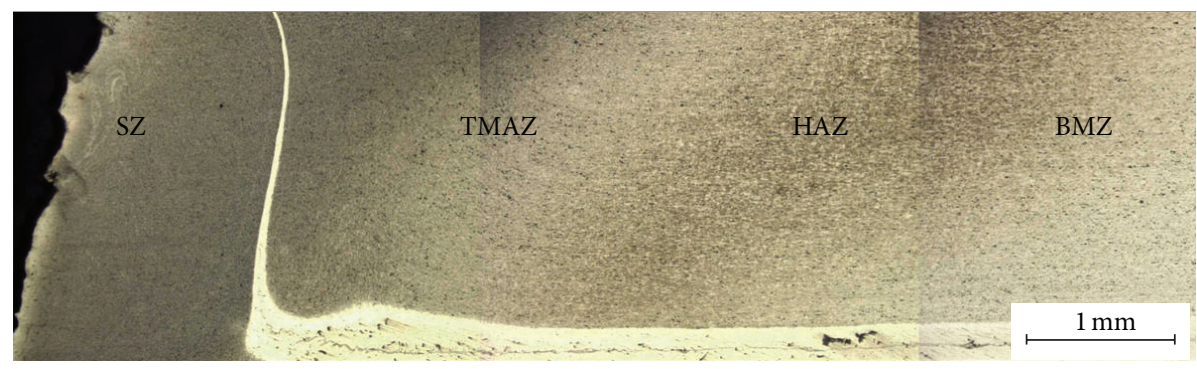

(a)

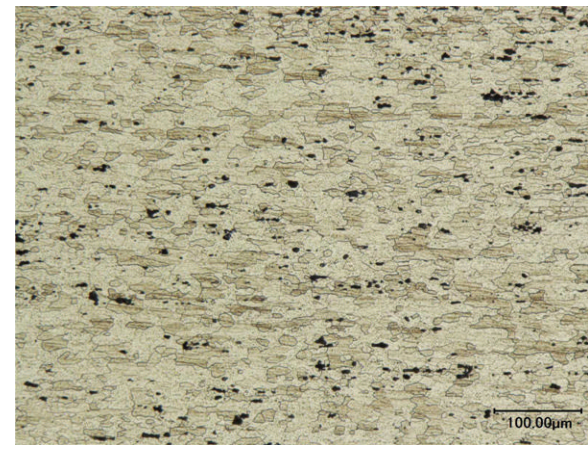

(b)

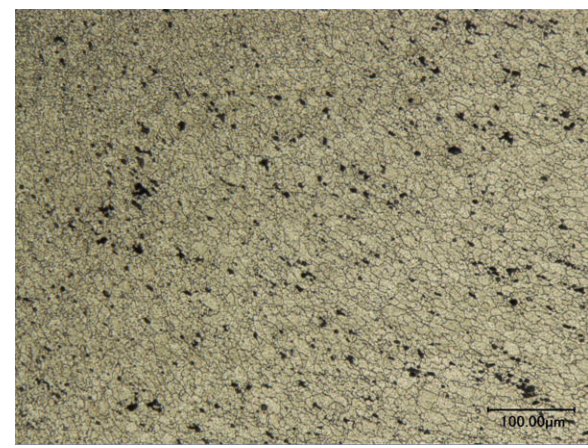

(d)

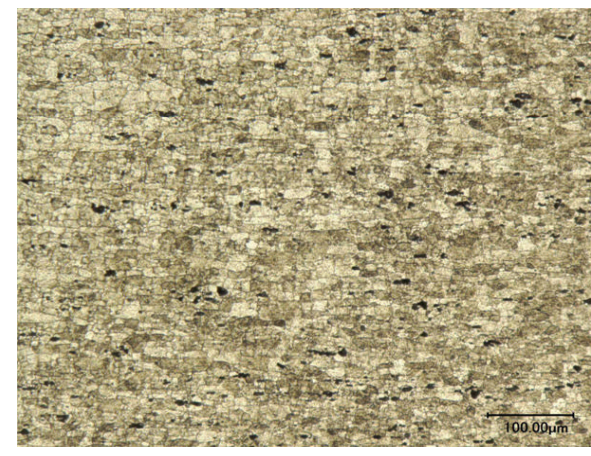

(c)

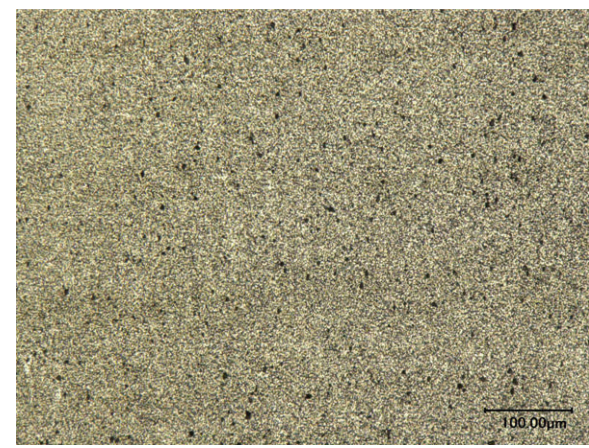

(e)

Figure 4: Microstructural photos of (a) cross-section, (b) BMZ, (c) HAZ, (d) TMAZ, and (e) SZ of a typical joint.

zone (TMAZ) and stir zone (SZ), as shown in Figure 4(a). In the BMZ, the grains are elongated and the second-phase particles are distributed parallel to the rolling direction (see Figure 4(b)). In the HAZ, no plastic deformation occurs in the FSSW process, the microstructure experiences overaging due to the welding heat effect, and thus the precipitates are coarsened and make HAZ darker than the BMZ (see Figure $4(c)$ ). The grains in the TMAZ are highly extruded in the FSSW process, and a material flowing pattern can be observed (see Figure 4(d)). Owning to a higher heat input, the second-phase particles in TMAZ are dissolved in the matrix and the quenching effect can occur during the rapid cooling. In the SZ, fine and equiaxed grains can be observed owing to dynamic recrystallization during FSSW (see Figure 4(e)), which implies that the SZ experiences high temperature and severe plastic deformation $[14,15]$.

3.1.2. Interface Bonding Regions. The bonding interface can be divided into three regions according to metallurgical

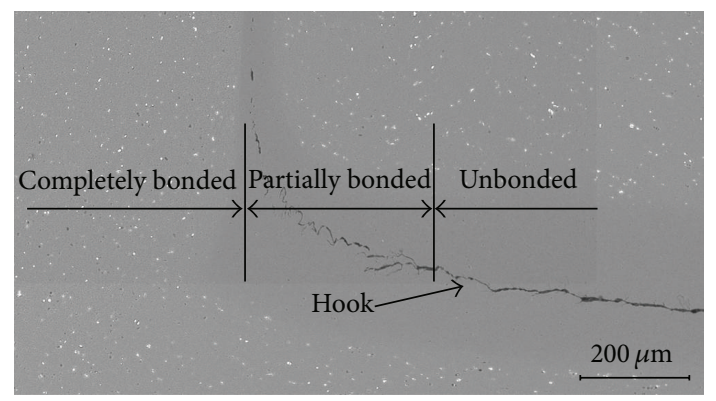

FIGURE 5: Interbonding regions of a typical joint.

bonding extent, that is, no bonding region, partial bonding region, and complete bonding region, as shown in Figure 5. In the no bonding region, there is no metallurgical bonding and the original interface is remained. In the partial bonding region, only partial metals are metallurgically bonded, and the original interface becomes discontinuous. In the complete 


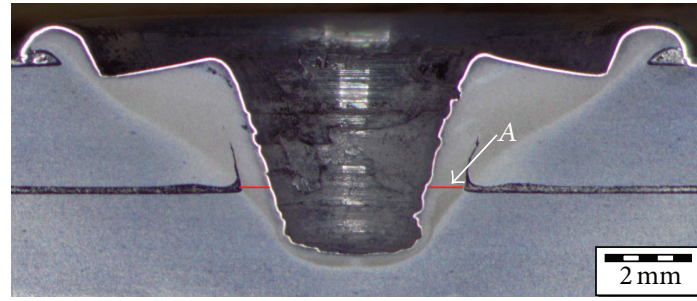

(a)

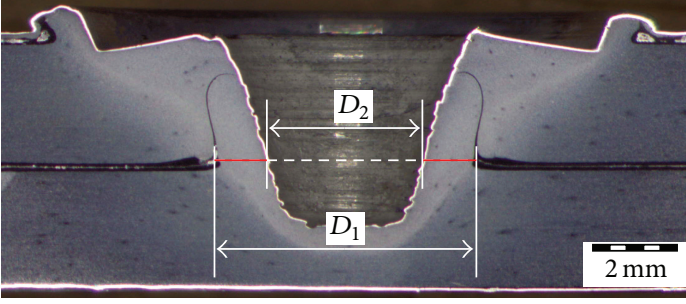

(b)

Figure 6: Cross-sections of the joints welded at the rotation speed of (a) $400 \mathrm{rpm}$ and (b) $800 \mathrm{rpm}$.

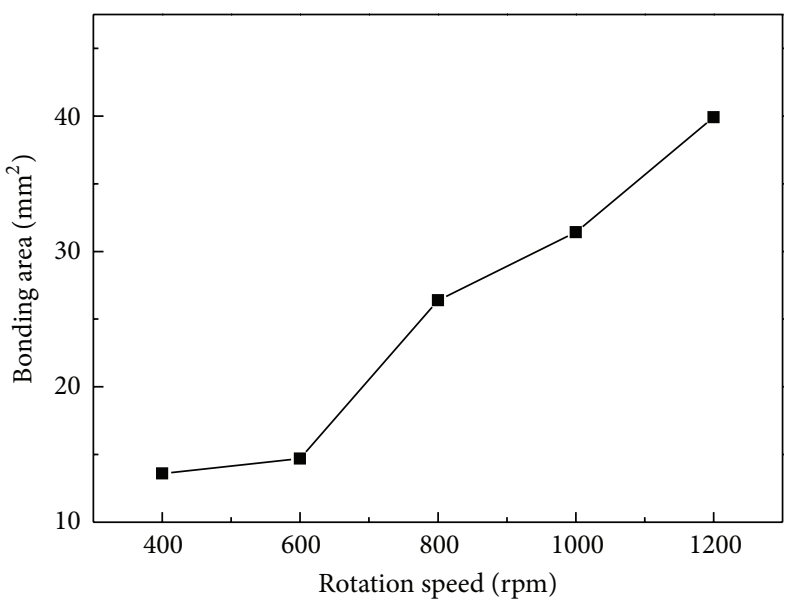

- Bonding area $20 \mathrm{~mm} / \mathrm{min}-0.3 \mathrm{~mm}$

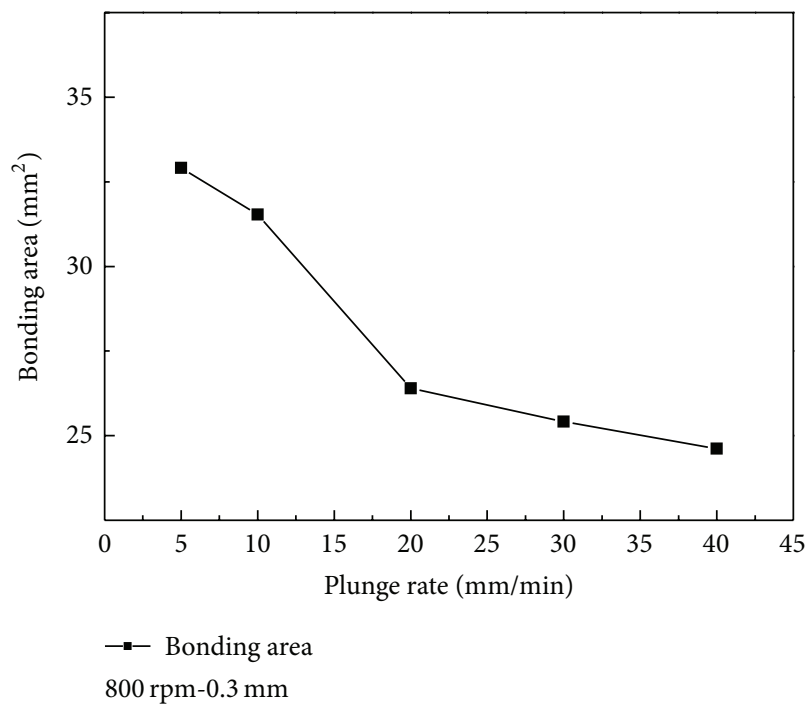

(b)

(a)

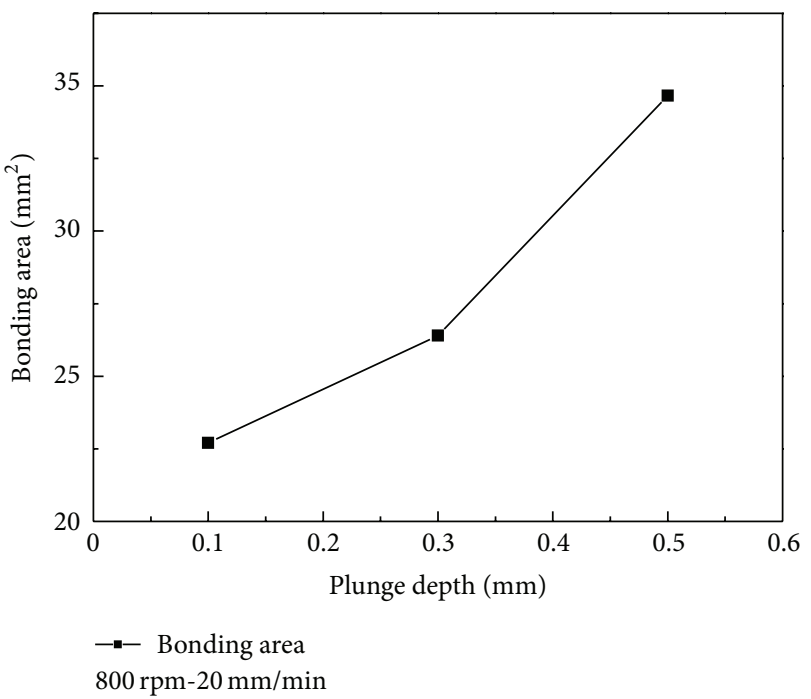

(c)

FIGURE 7: Bonding area of the joint as a function of (a) rotation speed, (b) plunge rate, and (c) shoulder plunge depth.

bonding region, the original interface is thoroughly broken, and the complete metallurgical bonding occurs.

It is noted that the area of complete bonding region at the interface is significantly affected by the FSSW parameters, as shown in Figure 6. For the sake of convenience, the area of complete bonding region is expressed as $A$, and $A$ can be calculated by the formula $A=\pi\left(D_{1}^{2}-D_{2}^{2}\right) / 4$, where $D_{1}$ and $D_{2}$ are marked in Figure 6(b). Figure 7 shows the changing trend of bonding area with the FSSW parameters. It can be seen that the bonding area increases with the increase of 


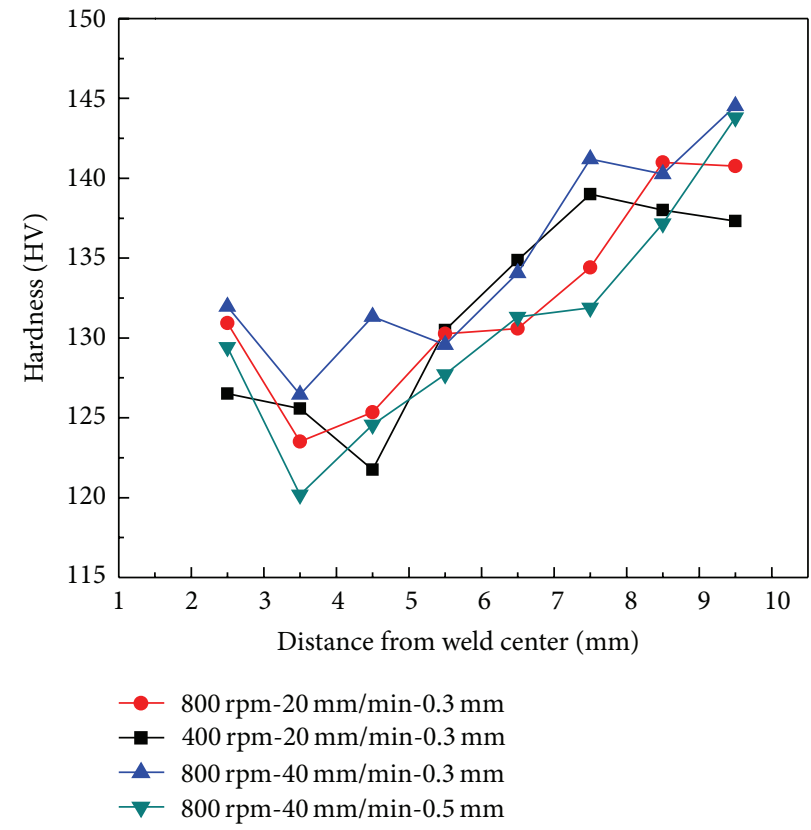

FIGURE 8: Microhardness distributions of the joints welded at different parameters.

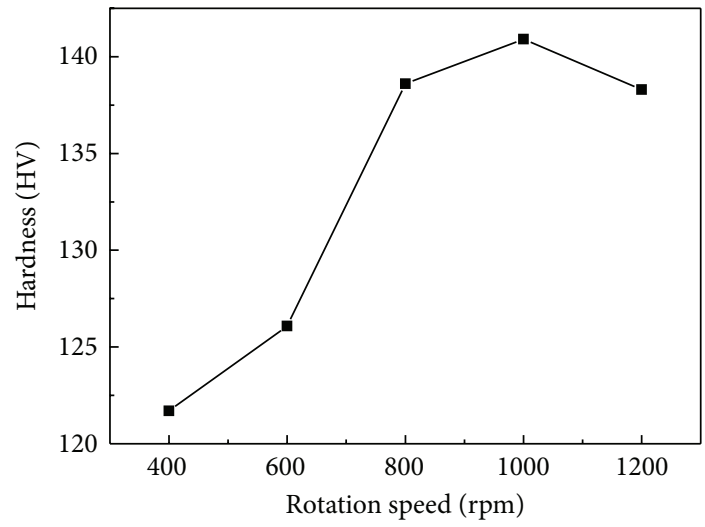

Average hardness value in SZ $20 \mathrm{~mm} / \mathrm{min}-0.3 \mathrm{~mm}$

(a)

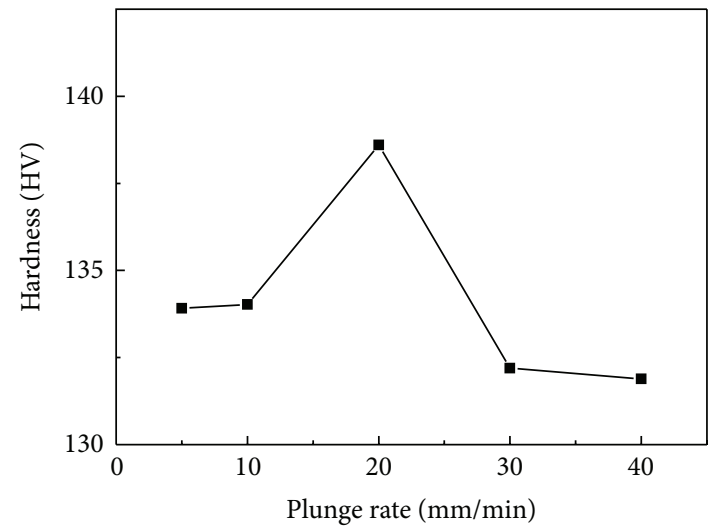

-- Average hardness value in SZ $800 \mathrm{rpm}-0.3 \mathrm{~mm}$

(b)

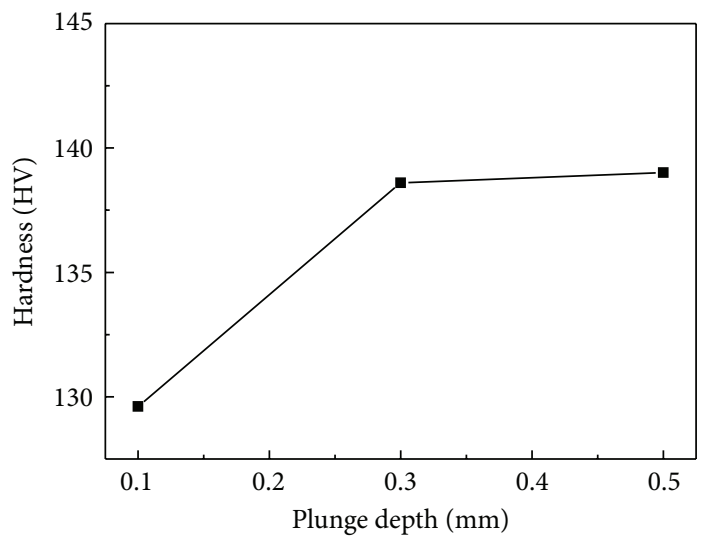

Average hardness value in SZ $800 \mathrm{rpm}-20 \mathrm{~mm} / \mathrm{min}$

(c)

Figure 9: Average hardness value in SZ as a function of (a) rotation speed, (b) plunge rate, and (c) shoulder plunge depth. 


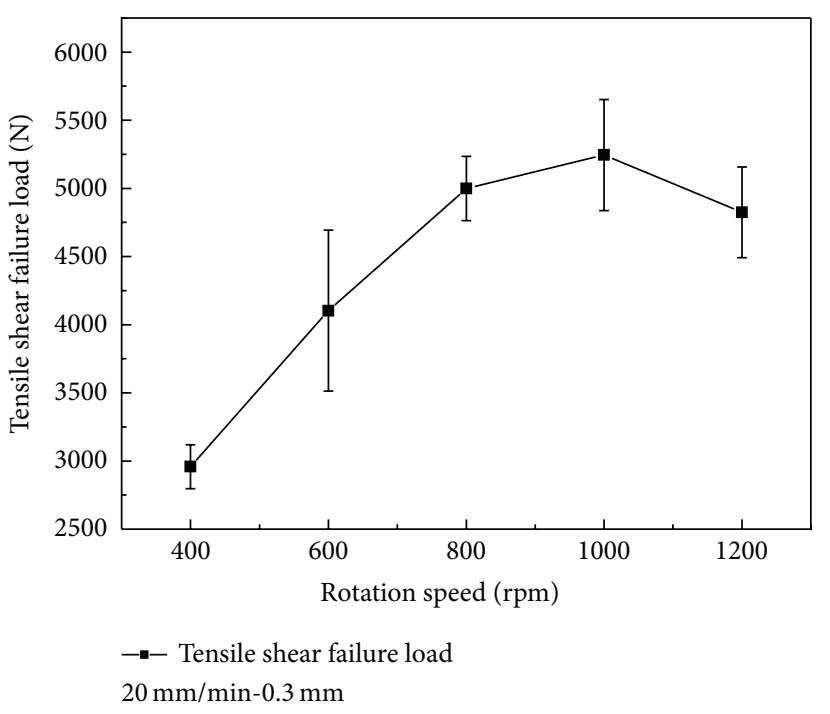

(a)

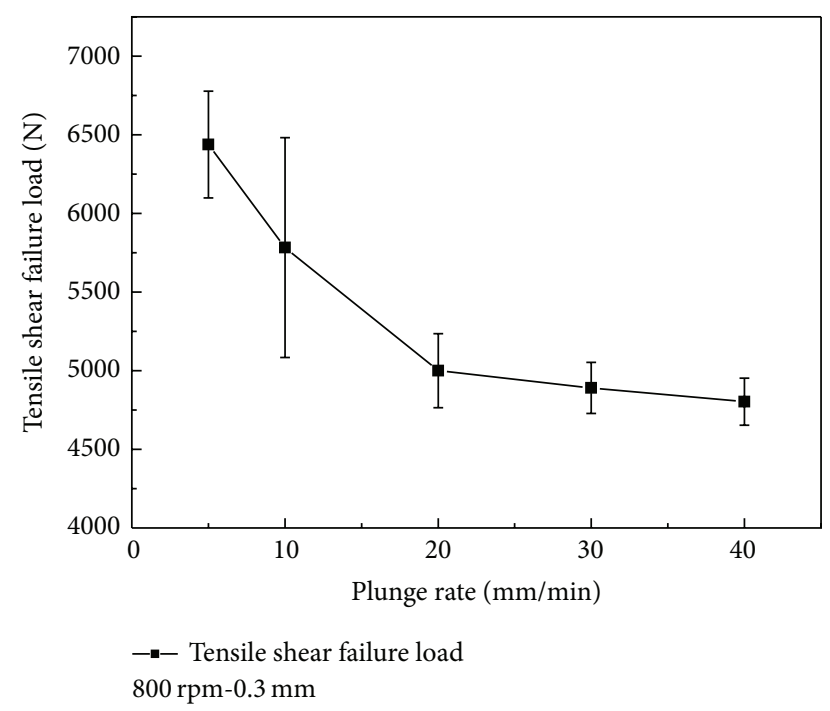

(b)

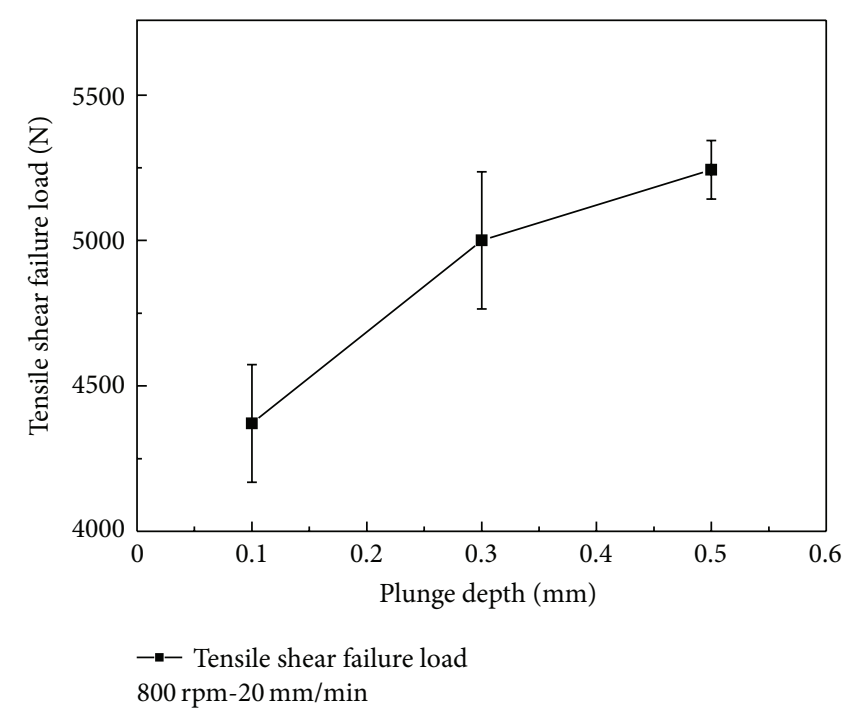

(c)

FIGURE 10: Tensile shear failure load of the joint as a function of (a) rotation speed, (b) plunge rate, and (c) shoulder plunge depth.

rotation speed and plunge depth (see Figures $7(\mathrm{a})$ and $7(\mathrm{c})$ ), but it decreases with increasing plunge rate (see Figure 7(b)). The reason for this is that the increasing welding heat input can improve the fluidity of plastic metal, and thus more interfaces can be mixed during FSSW.

\subsection{Mechanical Properties}

3.2.1. Microhardness Distributions. Figure 8 shows the hardness distributions of the joints welded at different parameters. A softened region that consisted of the HAZ, TMAZ, and SZ exists in all the joints, which is a typical characteristic for the FSSW joints of heat-treatable aluminum alloys $[16,17]$. In the softened region, the hardness first decreases from 135-145 HV to the minimum value lying in the TMAZ, and then increases in the SZ but still lower than that in the BMZ. All in all, the minimum hardness value decreases with increasing welding heat input.
With respect to $2 \mathrm{~A} 12$ aluminum alloy, precipitation strengthening is the predominant strengthening mechanism. The coarsening of the precipitates in the HAZ can weaken their strengthening effect, causing the hardness lower than that in the BMZ. In the TMAZ, the dissolution of the secondphase particles nearly eliminates the precipitation strengthening effect, and this is why the minimum hardness value is located in such a zone. During FSSW, dynamic recrystallization occurs in the SZ, and the fine grains can improve the metal strength. In addition, the second-phase particles dissolved can reprecipitate during the cooling stage owning to the higher heat input [18]. As a result, the hardness increases in the SZ, but still below that in the BMZ.

The metal of upper and lower sheets is stirred and metallurgically bonded in SZ, so the average hardness value in SZ is critical for mechanical properties of spot welded joint. It can be seen that, with the increase of rotation speed and plunge rate, the average hardness value in SZ firstly increases and 


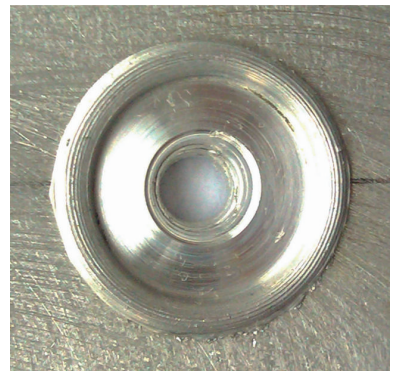

(a)

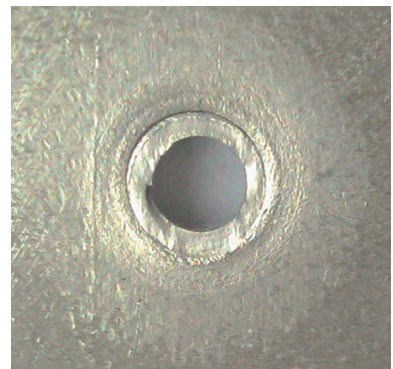

(b)

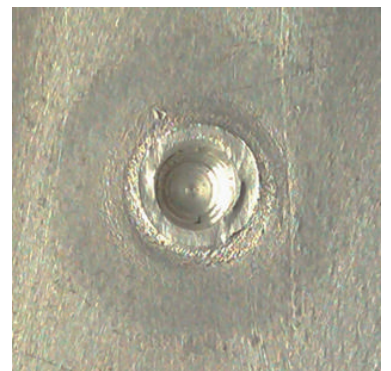

(c)

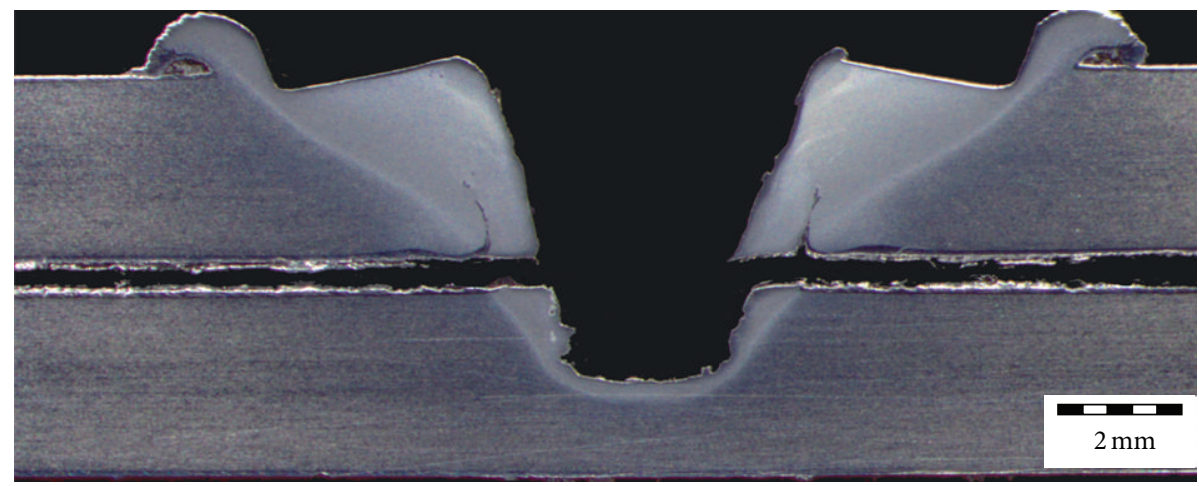

(d)

Figure 11: (a) Upper side of the upper sheet, (b) lower side of the upper sheet, (c) upper side of the lower sheet and (d) cross-section of the shear fracture specimen.

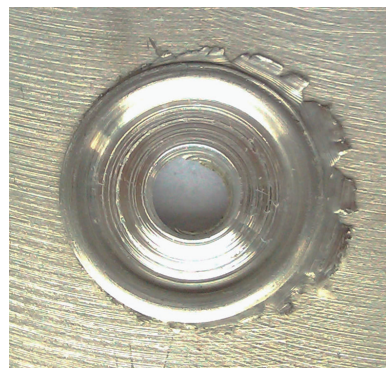

(a)

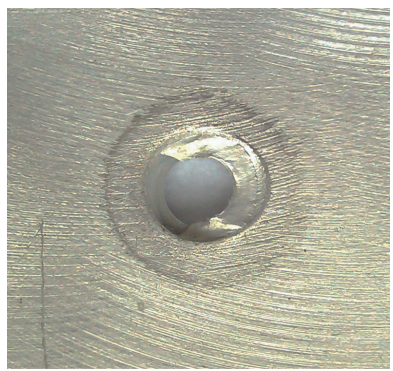

(b)

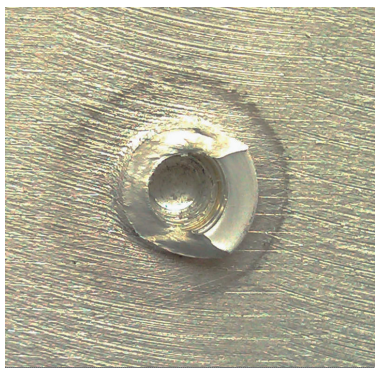

(c)

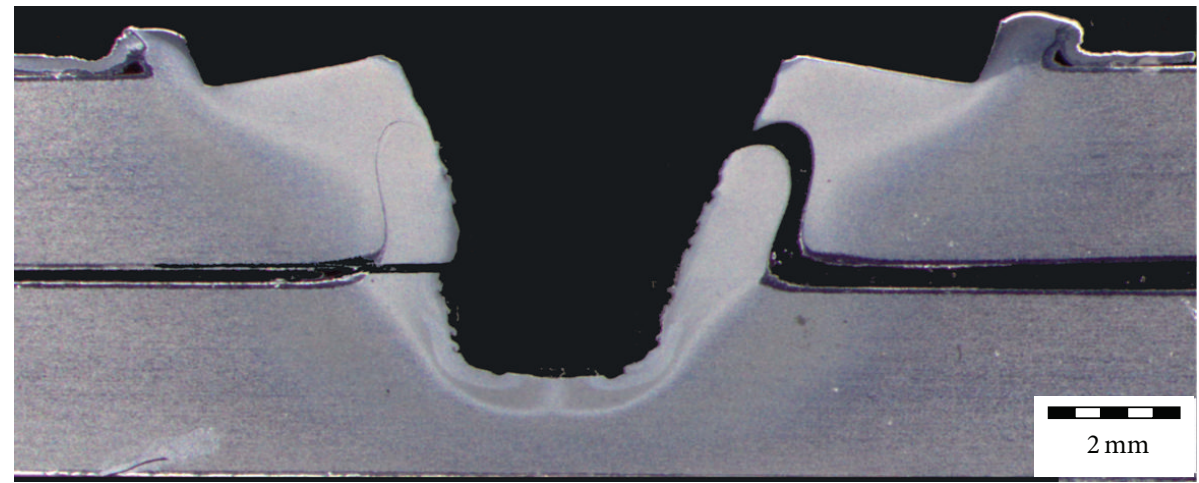

(d)

FIGURE 12: (a) Upper side of the upper sheet, (b) lower side of the upper sheet, (c) upper side of the lower sheet and (d) cross-section of the tensile-shear mixed fracture specimen. 
then decreases (see Figures 9(a) and 9(b)), and the average hardness value increases with the plunge depth (see Figure $9(\mathrm{c})$ ). And the average hardness value is determined by the dissolution and reprecipitation of second-phase particles and the final size of grains in SZ [18].

3.2.2. Tensile Shear Properties. Figure 10 shows the changing trends of the tensile shear failure load with the FSSW parameters. When the plunge rate and shoulder plunge depth are $20 \mathrm{~mm} / \mathrm{min}$ and $0.3 \mathrm{~mm}$, respectively, with the rotation speed increasing from 400 to $1200 \mathrm{rpm}$, the tensile shear failure load firstly increases to the maximum value of $5245 \mathrm{~N}$ at $1000 \mathrm{rpm}$ and then decreases with the further increase to $1200 \mathrm{rpm}$ (see Figure 10(a)). It is known that the tensile shear failure load is not only dependent on the bonding strength but also on the bonding area. And the bonding strength can be reflected by average hardness value in SZ. With the rotation speed increasing from 400 to $1000 \mathrm{rpm}$, the increasing bonding area and average hardness value in SZ can enhance the carrying capability of the joint accordingly the tensile shear failure load increases. However, when the rotation speed increases to $1200 \mathrm{rpm}$, although a larger bonding area is obtained, a higher welding heat input causes the average hardness value in SZ to decrease (see Figure 9(a)), and such a factor becomes dominant; therefore the tensile shear failure load decreases.

At the fixed rotation speed of $800 \mathrm{rpm}$ and shoulder plunge depth of $0.3 \mathrm{~mm}$, the tensile shear failure load decreases with the increase of plunge rate, and the bonding area is the dominant factor. The maximum tensile shear failure load is obtained at the plunge rate of $5 \mathrm{~mm} / \mathrm{min}$, which is $6438 \mathrm{~N}$ (see Figure 10(b)). At the fixed rotation speed of $800 \mathrm{rpm}$ and plunge rate of $20 \mathrm{~mm} / \mathrm{min}$, the tensile shear failure load increases with increasing shoulder plunge depth, and the maximum value is $5243 \mathrm{~N}$ (see Figure 10(c)), and both the bonding area and average hardness value in SZ play a similar trend. It can be found by comparing Figures 7 and 9 with Figure 10 that the carrying capability of the spot welded joints can be improved by appropriately increasing welding heat input. The tensile shear failure load of the optimal FSSW joint is $6438 \mathrm{~N}$, and it is almost equal to that of similar joints produced by resistance spot welding $(6459 \mathrm{~N})$ and lower than that of riveted joints $(8514 \mathrm{~N})$. [19].

3.2.3. Fracture Features. Two kinds of failure modes can be observed in the tensile shear tests, that is, shear fracture and tensile-shear mixed fracture. At the fixed plunge rate of $20 \mathrm{~mm} / \mathrm{min}$ and at the shoulder plunge depth of $0.3 \mathrm{~mm}$, shear fracture occurs only at a lower rotational speed of $400 \mathrm{rpm}$, as shown in Figure 11. The corresponding tensile shear failure load and the bonding area are only $2958 \mathrm{~N}$ and $13.6 \mathrm{~mm}^{2}$, respectively. With the rotational speed increasing from $600 \mathrm{rpm}$ to $1200 \mathrm{rpm}$, tensile-shear mixed fracture mode is dominant, as shown in Figure 12, and the corresponding tensile shear failure load and bonding area increase obviously. This implies that a high quality FSSW joint should be fractured in the tensile-shear mixed mode during the tensile shear test.

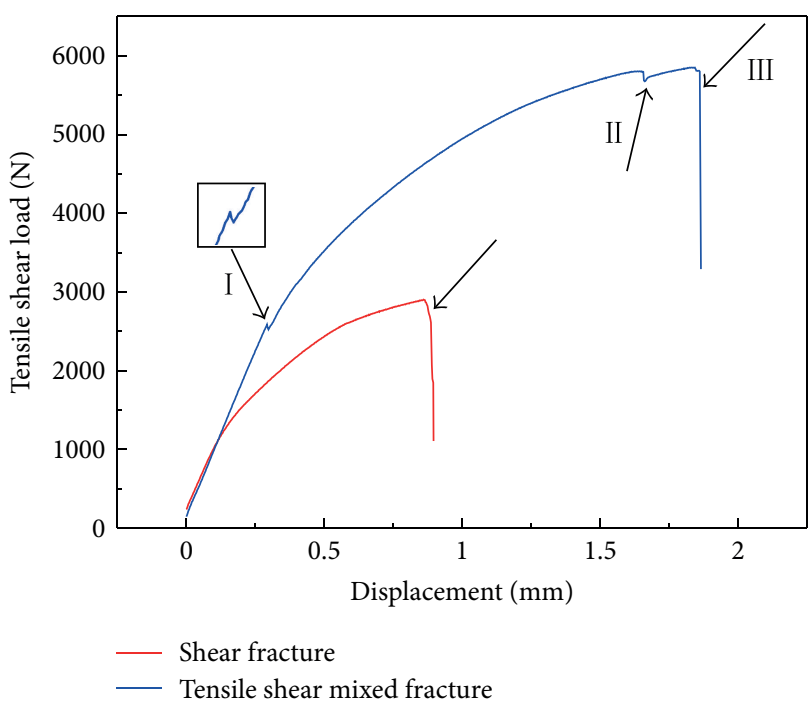

FIGURE 13: Typical load-displacement curves of FSSW joints fractured in the two different modes.

Figure 13 shows the typical load-displacement curves of FSSW joints fractured in the two different modes. For the joint fractured in the shear mode, there is only one sharp drop on the load-displacement curve, as marked with an arrow in the lower curve in Figure 13, and the crack initiates and propagates through the bonding interface (see Figure 14(a)) owing to the small bonding area. For the joint fractured in the tensile-shear mixed mode, there are three sharp drops on the load-displacement curve in Figure 13, which correspond to the three stages of the crack propagation (see Figure 14(b)). In the first stage as shown by CI in Figure 14(b), the crack first initiates at the tip of the hook and propagates upwards along the hook because the oxide particles and partial bonding exit in the hook. This is a tensile crack and is reflected by the first sharp drop on the load-displacement curve in Figure 13. With the continuous increase of the test load, the crack propagation comes into the second stage, and the crack path is shown by CII in Figure 14(b). The crack propagates through the bonding area, and a typical shear fracture occurs, which is reflected by the second sharp drop on the load-displacement curve in Figure 13. When the test load is continuously increased, the crack propagation comes into the third stage, and the crack path is shown by CIII in Figure 14(b). This is a tensile-shear fracture and is reflected by the third sharp drop on the loaddisplacement curve in Figure 13.

The SEM micrographs of fracture surfaces in different modes are shown in Figure 15. Figure 15(a) shows the fracture surface of the joint failed in the bonding interface. The tear ridges exist, and the brittle fracture is dominant. It is indicated that quasi-cleavage fracture occurs due to the face-centered cubic structure of aluminum alloys. Similar fracture feature can be observed in the fracture surface of the SZ failed in the tensile-shear fracture mode (see Figure 15(b)). Figure 15(c) shows the fracture surface of the joint failed through the hook. Such a fracture surface is very smooth, which indicates that the original interface exists in the hook. 


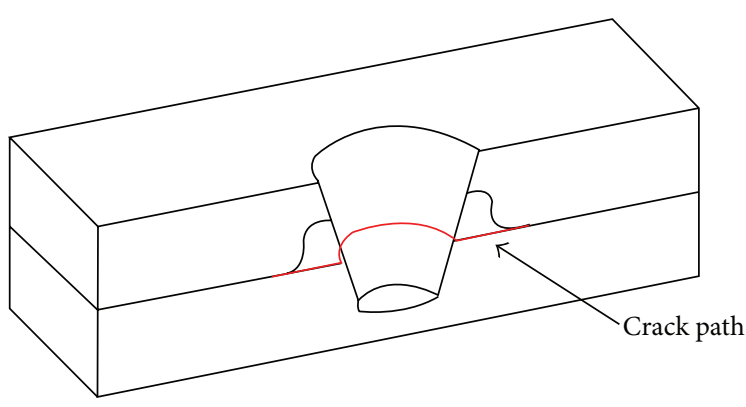

(a)

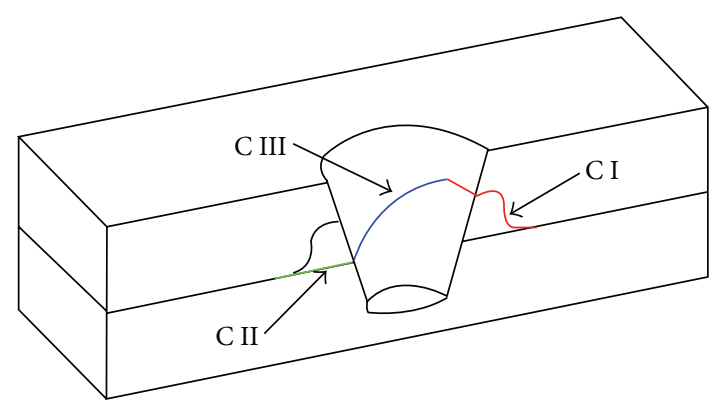

(b)

FIGURE 14: Schematic diagram of crack propagation of (a) shear fracture mode and (b) tensile-shear mixed fracture mode.

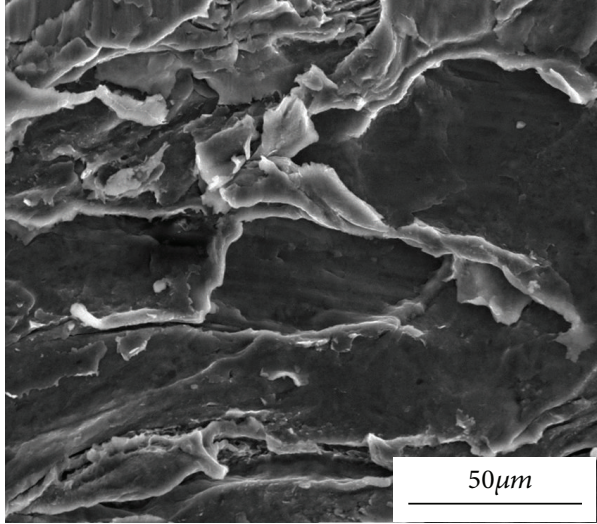

(a)

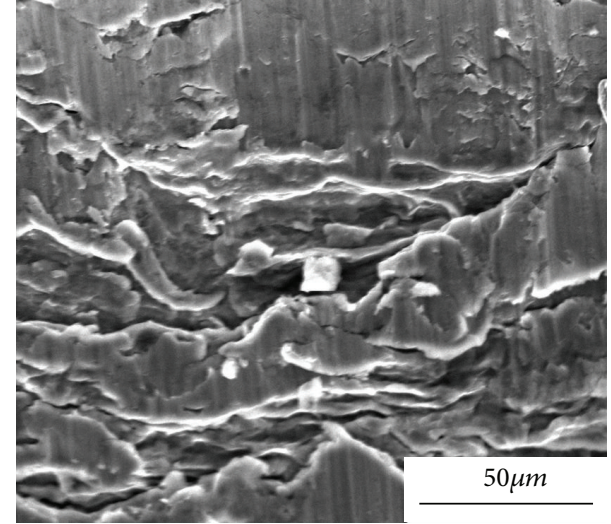

(b)

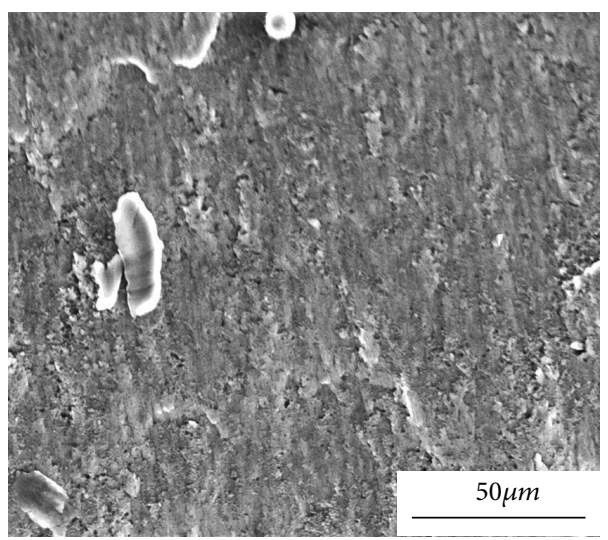

(c)

FIGURE 15: Fracture surfaces failed in the (a) bonding interface, (b) SZ and (c) hook of FSSW joints.

\section{Conclusions}

Microstructural characteristics and mechanical properties of friction stir spot welded 2A12-T4 aluminum alloy were investigated, and the conclusions can be drawn as follows.

(1) The bonding interface can be divided into three regions according to metallurgical bonding extent, that is, no bonding region, partial bonding region, and complete bonding region. The area of complete bonding region at the interface increased with the welding heat input because more interface metals were mixed.
(2) A softened microstructural region existed in the joint, and it consisted of SZ, TMAZ, and HAZ. The minimum hardness was located in the TMAZ, and the average hardness value in $\mathrm{SZ}$ can be improved by appropriately increasing welding heat input.

(3) The tensile shear failure load of the joint increased with increasing rotation speed from 400 to $1000 \mathrm{rpm}$, but it decreased with increasing plunge rate from 5 to $40 \mathrm{~mm} / \mathrm{min}$ or decreasing shoulder plunging depth from 0.5 to $0.1 \mathrm{~mm}$. The carrying capability can be 
improved by appropriately increasing welding heat input.

(4) Two kinds of failure modes, that is, shear fracture mode and tensile-shear mixed fracture mode, can be observed in the tensile shear tests. With the welding heat input increasing, the failure mode changed from the shear fracture to the tensile-shear mixed fracture, and the tensile shear failure load of the joint increased.

\section{Acknowledgments}

The authors are grateful to be supported by the National Natural Science Foundation of China (51175117), by the National Basic Research Program of China (2010CB731704), and by the National Science and Technology Major Project of China (2010ZX04007-011).

\section{References}

[1] W. Yuan, R. S. Mishra, S. Webb et al., "Effect of tool design and process parameters on properties of Al alloy 6016 friction stir spot welds," Journal of Materials Processing Technology, vol. 211, no. 6, pp. 972-977, 2011.

[2] D. Mitlin, V. Radmilovic, T. Pan, J. Chen, Z. Feng, and M. L. Santella, "Structure-properties relations in spot friction welded (also known as friction stir spot welded) 6111 aluminum," Materials Science and Engineering A, vol. 441, no. 1-2, pp. 79-96, 2006.

[3] S. G. Arul, S. F. Miller, G. H. Kruger, T. Y. Pan, P. K. Mallick, and A. J. Shih, "Experimental study of joint performance in spot friction welding of 6111-T4 aluminium alloy," Science and Technology of Welding and Joining, vol. 13, no. 7, pp. 629-637, 2008.

[4] S. Lathabai, M. J. Painter, G. M. D. Cantin, and V. K. Tyagi, "Friction spot joining of an extruded $\mathrm{Al}-\mathrm{Mg}-\mathrm{Si}$ alloy," Scripta Materialia, vol. 55, no. 10, pp. 899-902, 2006.

[5] Y. Tozaki, Y. Uematsu, and K. Tokaji, "Effect of processing parameters on static strength of dissimilar friction stir spot welds between different aluminium alloys," Fatigue and Fracture of Engineering Materials and Structures, vol. 30, no. 2, pp. 143148, 2007.

[6] S. G. Arul, T. Y. Pan, P. -C. Lin, J. Pan, Z. Feng, and M. L. Santela, "Microstructures and failure mechanisms of spot friction welds in lap-shear specimens of aluminum 5754 sheets," in Proceedings of the SAE World Congress and Exhibition, Detroit, Mich, USA, April 2005.

[7] Z. Zhang, X. Yang, J. Zhang, G. Zhou, X. Xu, and B. Zou, "Effect of welding parameters on microstructure and mechanical properties of friction stir spot welded 5052 aluminum alloy," Materials and Design, vol. 32, no. 8-9, pp. 4461-4470, 2011.

[8] Y. Tozaki, Y. Uematsu, and K. Tokaji, "Effect of tool geometry on microstructure and static strength in friction stir spot welded aluminium alloys," International Journal of Machine Tools and Manufacture, vol. 47, no. 15, pp. 2230-2236, 2007.

[9] M. Merzoug, M. Mazari, L. Berrahal, and A. Imad, "Parametric studies of the process of friction spot stir welding of aluminium 6060-T5 alloys," Materials and Design, vol. 31, no. 6, pp. 30233028, 2010.

[10] Y. H. Yin, N. Sun, T. H. North, and S. S. Hu, "Influence of tool design on mechanical properties of AZ31 friction stir spot welds," Science and Technology of Welding and Joining, vol. 15, no. 1, pp. 81-86, 2010.
[11] H. Badarinarayan, Q. Yang, and S. Zhu, "Effect of tool geometry on static strength of friction stir spot-welded aluminum alloy," International Journal of Machine Tools and Manufacture, vol. 49, no. 2, pp. 142-148, 2009.

[12] H. Badarinarayan, Y. Shi, X. Li, and K. Okamoto, "Effect of tool geometry on hook formation and static strength of friction stir spot welded aluminum 5754-O sheets," International Journal of Machine Tools and Manufacture, vol. 49, no. 11, pp. 814-823, 2009.

[13] G. Buffa, G. Campanile, L. Fratini, and A. Prisco, "Friction stir welding of lap joints: influence of process parameters on the metallurgical and mechanical properties," Materials Science and Engineering A, vol. 519, no. 1-2, pp. 19-26, 2009.

[14] H. J. Zhang, H. J. Liu, and L. Yu, "Microstructure and mechanical properties as a function of rotation speed in underwater friction stir welded aluminum alloy joints," Materials and Design, vol. 32, no. 8-9, pp. 4402-4407, 2011.

[15] J. Q. Su, T. W. Nelson, and C. J. Sterling, "Microstructure evolution during FSW/FSP of high strength aluminum alloys," Materials Science and Engineering A, vol. 405, no. 1-2, pp. 277286, 2005.

[16] H. J. Liu, H. J. Zhang, and L. Yu, "Homogeneity of mechanical properties of underwater friction stir welded 2219-T6 aluminum alloy," Journal of Materials Engineering and Performance, vol. 20, no. 8, pp. 1419-1422, 2011.

[17] Y. C. Chen, A. Gholinia, and P. B. Prangnell, "Interface structure and bonding in abrasion circle friction stir spot welding: a novel approach for rapid welding aluminium alloy to steel automotive sheet," Materials Chemistry and Physics, vol. 134, no. 1, pp. 459463, 2012.

[18] Y. C. Chen, J. C. Feng, and H. J. Liu, "Precipitate evolution in friction stir welding of 2219-T6 aluminum alloys," Materials Characterization, vol. 60, no. 6, pp. 476-481, 2009.

[19] MIL Military Handbook:MIL-HDBK-5H-Metallic Materials and Elements for Aerospace Vehicle Structures, chapter 8, 1998. 

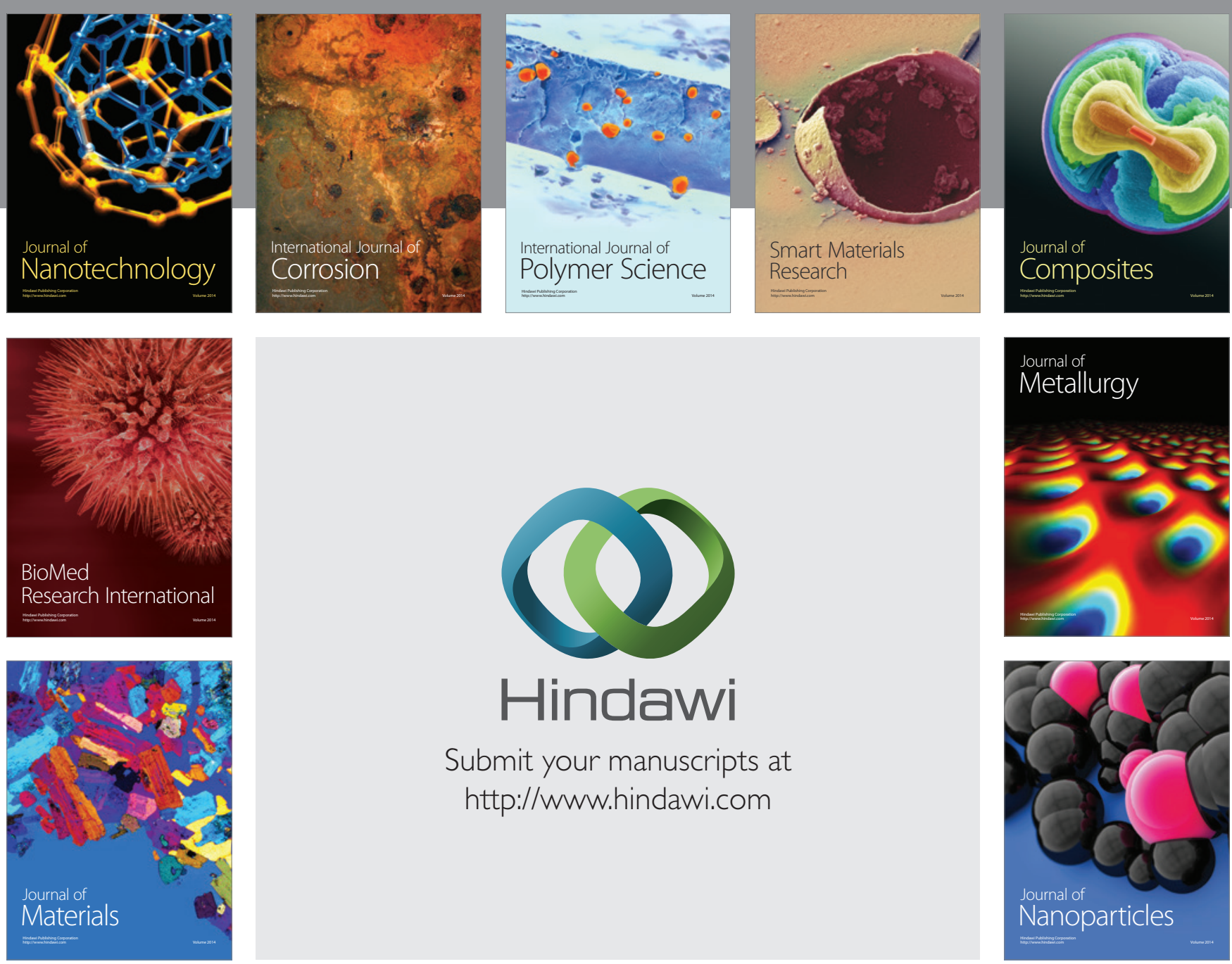

Submit your manuscripts at http://www.hindawi.com
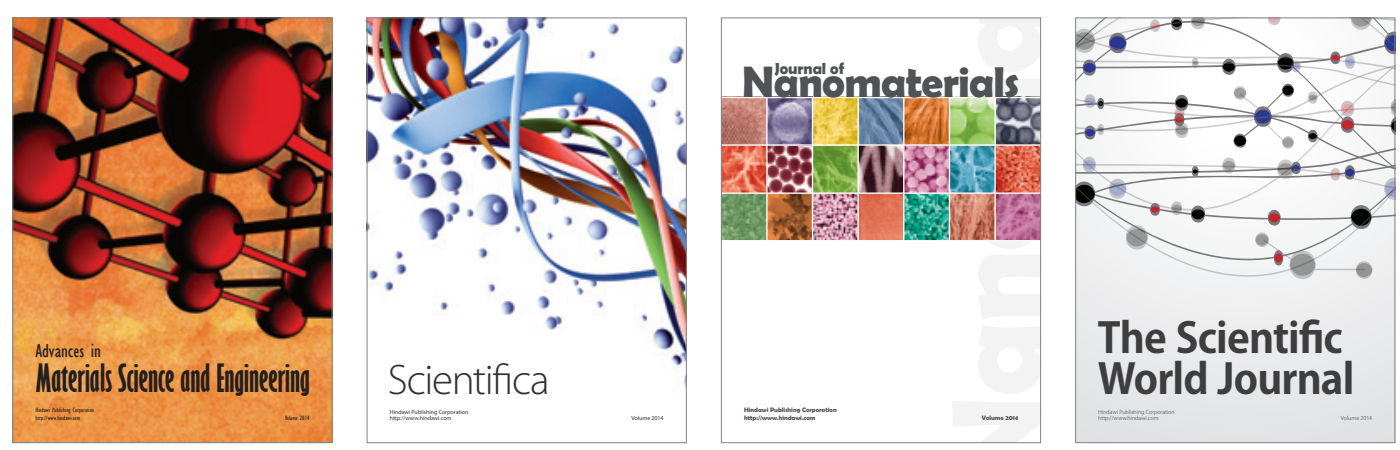

\section{The Scientific World Journal}
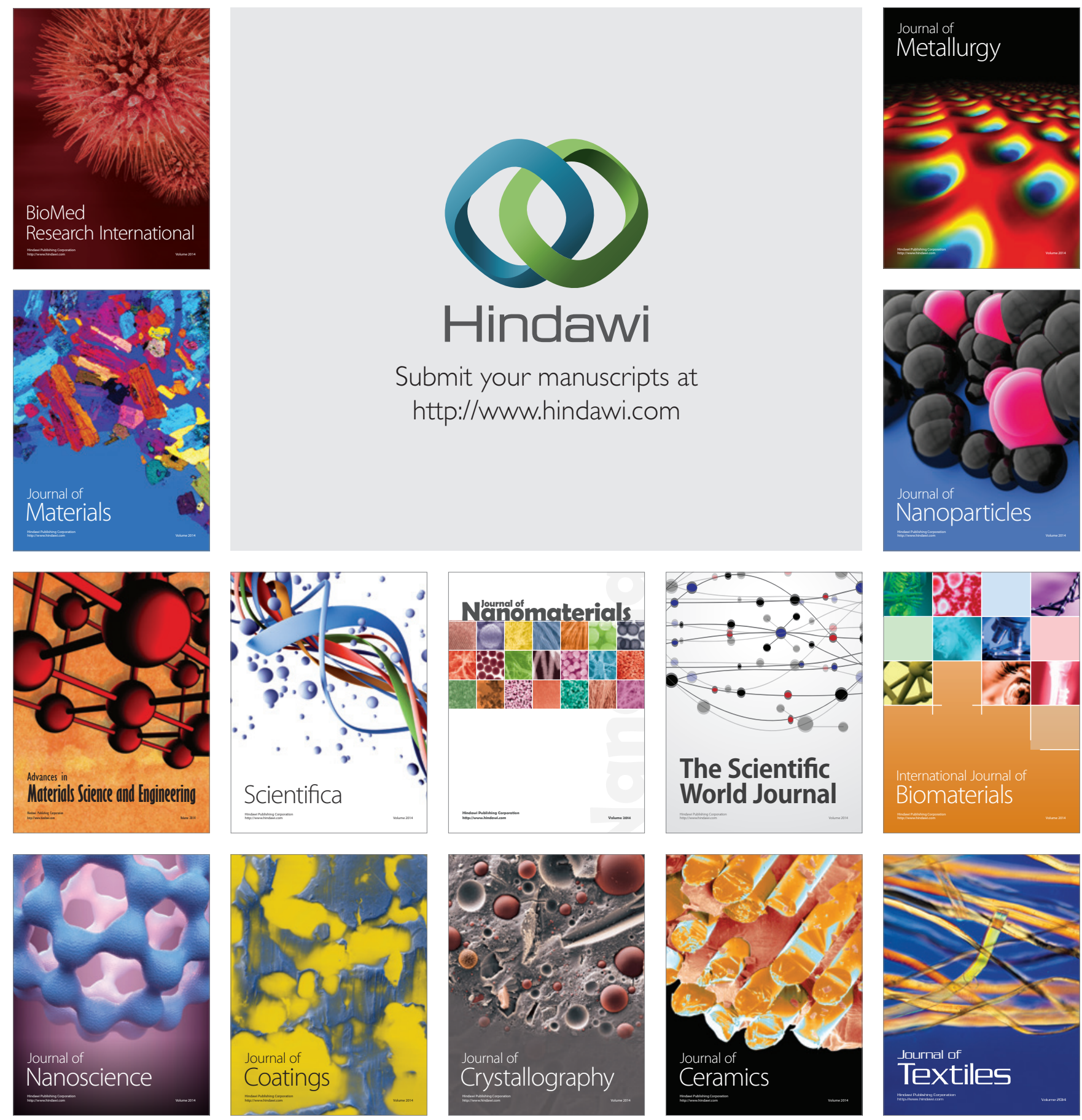